Emerging Materials Research Volume 1 Issue EMR2

The role of controlled interfaces in the thermal management of copper-carbon composites Silvain et al.
Pages 75-88 http://dx.doi.org/10.1680/emr.11.00016 Themed Issue Paper

Received 03/11/2011

Published online 13/01/2012

Keywords: thermal properties/composite materials/material

processing

\title{
The role of controlled interfaces in the thermal management of copper-carbon composites
}

\author{
Jean-François Silvain \\ Université Bordeaux 1, Institut de Chimie de la Matière Condensée de \\ Bordeaux (ICMCB), CNRS, France

\section{Amélie Veillere} \\ Université Bordeaux 1, Institut de Chimie de la Matière Condensée de \\ Bordeaux (ICMCB), CNRS, France \\ Jean-Marc Heintz \\ Université Bordeaux 1, Institut de Chimie de la Matière Condensée de \\ Bordeaux (ICMCB), CNRS, France

\section{Cécile Vincent} \\ Université Bordeaux 1, Institut de Chimie de la Matière Condensée de \\ Bordeaux (ICMCB), CNRS, France \\ Thomas Guillemet \\ Université Bordeaux 1, Institut de Chimie de la Matière Condensée de \\ Bordeaux (ICMCB), CNRS, France
}

Department of Mechanical and Materials Engineering, University of Nebraska - Lincoln, USA

Department of Electrical Engineering, University of Nebraska Lincoln, USA

\section{Guillaume Lacombe}

Université Bordeaux 1, Institut de Chimie de la Matière Condensée de Bordeaux (ICMCB), CNRS, France

Yongfeng Lu

Department of Electrical Engineering, University of Nebraska Lincoln, LUSA

\section{Namas Chandra}

Department of Mechanical and Materials Engineering, University of Nebraska - Lincoln, USA

The increase in both power and packing densities in power electronic devices has led to an increase in the market demand for effective heat-dissipating materials, with high thermal conductivity and thermal- expansion coefficient compatible with chip materials still ensuring the reliability of the power modules. In this context, metal matrix composites: carbon fibers, carbon nano fibers and diamond-reinforced copper matrix composites among them are considered very promising as a next generation of thermal-management materials in power electronic packages. These composites exhibit enhanced thermal properties compared to pure copper combined with lower density. This article presents the fabrication techniques of copper/carbon composite films by powder metallurgy and tape casting and hot pressing; these films promise to be efficient heat-dissipation layers for power electronic modules. The thermal analyses clearly indicate that interfacial treatments are required in these composites to achieve high thermomechanical properties. Interfaces (through novel chemical and processing methods), when selected carefully and processed properly will form the right chemical/mechanical link between copper and carbon, enhancing all the desired thermal properties while minimizing the deleterious effect. In this paper, a variety of methods that are system specific that achieve these goals are outlined.

\section{Introduction}

Electronic packaging refers to the protective features and safety devices that enable continued and efficient operation of electronic components, and does not refer to shipping containers. Electronic components typically refer to assemblage of resistors, capacitors, transistors, diodes, and so on, in a complex well-designed group as integrated circuits usually soldered to a printed circuit board. As these components are very sensitive in all respects, the packaging is designed to prevent damage, avoid exposure to dirt and other adverse environment, dissipate heat very efficiently, enhance reliable service life and sustain efficient working conditions.

Electronic components and devices dominate our modern life in every possible way. The semiconductor (electronic) industry has been the key driver for the economic growth of many developed and developing nations. Worldwide scale of this industry in 2009 is in the range of US\$226 Billion, with an expected growth rate of $8 \%$ to $10 \%$ per year. Electronic products range from consumer electronics to products in virtually every possible commercial and industrial sector. There is not a person alive today who is not touched by electronic devices, unless he or she is a cave dweller. There is a constant drive to shrink the feature sizes and pack more and more electronic components inside the silicon chip. The industry is involved in an endless search of new materials that enable electronic systems with ever-increasing density of components, through higher heat-dissipation capability, lower density, and higher reliability. The new materials have to match the coefficient of thermal expansion (CTE) of materials currently 
Emerging Materials Research

Volume 1 Issue EMR2
The role of controlled interfaces in

the thermal management of

copper-carbon composites

Silvain et al. used in electronic packaging components, ceramic substrates, $\mathrm{Si}$, $\mathrm{SiC}$ and other semiconductors, and so on. In fact, today, reliability appears as one of the major problems that affect the electronics, microelectronics, telecom, automotive and aeronautic industries. Specifically in these industries, thermal management is an increasingly critical part of achieving competitive functionality. It impacts speed, size, weight and reliability of components that will need to dissipate heat from currents and packaging densities, an order of magnitude higher than that in use today (Luedtke, 2004; Geffroy and Silvain, 2007; Mathias et al., 2009; Zweben, 1998).

Figure 1 shows the schematic representation of a modern electronic device. The silicon chip represents the electronic component where the heat is produced, and this chip needs to be maintained in a stress-free condition with a temperature below $100^{\circ} \mathrm{C}$. When the material of the chip is silicon carbide, then a temperature up to $250^{\circ} \mathrm{C}$ is acceptable. To avoid any stress, materials in contact with the chip should have a CTE of $4 \times 10^{-6} /{ }^{\circ} \mathrm{C}$, that of Silicon. As shown in the figure, direct-bonded copper (DBC; $\mathrm{Cu}-\mathrm{Al}_{2} \mathrm{O}_{3}-\mathrm{Cu}$ ), which has a CTE of $7 \times 10^{-6} /{ }^{\circ} \mathrm{C}$, is in contact with the chip. DBC comprises of ceramic (alumina or aluminum nitride) sandwiched by a thin layer of copper on either side. DBC has good electrical insulation and good heat-spreading characteristics that closely matches the CTE of the chip. However, when using alumina, the thermal conductivity in the critical normal direction is on the order of $30 \mathrm{~W} / \mathrm{mK}$ whereas for aluminum nitride, it is on the order of 120 $\mathrm{W} / \mathrm{mK}$. However, because of cost considerations, the latter is used only when absolutely essential. There is still a need for developing a less expensive DBC with high $k$ values.

Composite materials show the highest potential for application in heat sinks for electronic applications. They can combine metal, polymer and ceramics in a broad range of different products and can be tailored to the final desired properties. It is critically important to note that final properties of composites depend not only on the basic constitutent materials but also on the methods of manufacture. Among the large number of different composites, the most efficient and the most commonly developed for heat-dissipation purposes are metal matrix composites (MMCs). More specifically MMCs based on copper and aluminum matrices with a broad range of different reinforcements show great promise. In general, MMCs

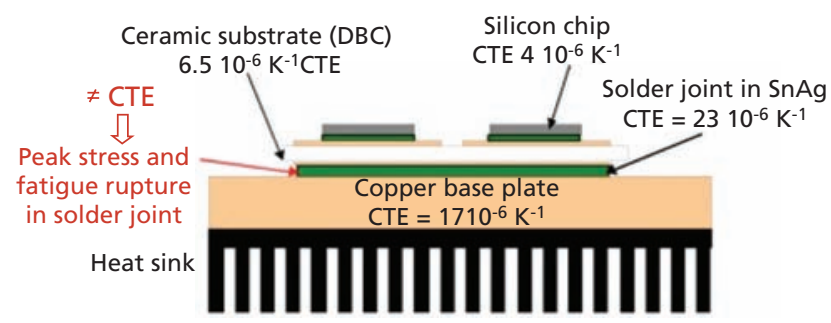

Figure 1. Design of microelectronic devices with peak stress in solder joint. show several improvements in comparison with currently used materials in electronic packaging, including the following:

- Lower and tailorable CTE (the higher the volume fraction of reinforcement used, the lower the CTE),

- Higher heat dissipation capability,

- Light weight, suitable for space applications,

- Higher stiffness at elevated temperatures (for dimensional stabilities at elevated temperatures).

Because of their high conductivity, low CTE and light weight, Al/ $\mathrm{SiC}_{\mathrm{p}}\left(50 \%-70 \% \mathrm{SiC}_{\mathrm{p}}\right)$ composites represent one of the MMCs that have quickly found real industrial applications (Saums, 2004; Zweben, 2006). Recently, these MMCs have been formed into a variety of shapes and sizes using a combination of infiltration and squeeze-casting forming methods. Unfortunately, as these materials cannot be easily machined, they have to be formed near-net shape restricting their widespread use. Another interesting $\mathrm{MMC}$ is $\mathrm{Cu} /$ diamond composites (Chu et al., 2010; Schubert et al., 2008; Weber and Tavangar, 2007); however, they are expensive and difficult to machine. Copper-based materials are the most promising among MMCs (PLANSEE, 2009; Veillère, 2009; Vincent, 2008; Silvain et al., 2010; Zweben, 2006). Most of the composites based on this matrix are reinforced by ceramics (particles, short fibers and long fibers) to reduce their extremely high CTE in an effort to match with that of the semiconductor or other ceramic substrates. As carbon fibers have both high thermal and electrical conductivity, MMCs reinforced with long carbon fibers show excellent thermal conductivity along the fiber direction. Unfortunately, these composites are restricted to a narrower range of heat sinks as the excellent $k$ is achieved only along the surface (fiber direction) but not across the thickness. In general, particle-reinforced MMCs have isotropic properties with only modest increase in properties. In addition, particle MMCs are easy to manufacture and are inexpensive.

In this paper, the main focus is on understanding the thermalmanagement requirements of electronic packaging, the key scientific and technological issues, advances in terms of materials, design and processing, and future prospects of the field. In specific, how the competing physical, mechanical and thermal requirements are optimized in heat sinks will be addressed. Many of the issues addressed can be equally applicable to the design of any component with similar thermal and mechanical requirements including that of heat-exchanger tubes. Although in this paper, the main focus is on copper-carbon system, concepts presented here can be easily extended to other material systems.

It turns out the interphase naturally occurs between matrix and reinforcements when they are reactive; however, in copper-carbon system, the interphases have to be carefully designed to enhance structural, thermal and electrical properties. The selection of interphase chemistry and processing methods depend on the type of 
copper (type and particle/dendrite distribution) and carbon (micro/ nano fiber, diamond). For each combination, a very carefully selected interface chemistry and processing method have to be designed not only in the raw material preparation stage but also in the final product development stages. In the next section, novel chemical routes that have been devised for nano fibers, regular micro fibers and diamonds is described. Different manufacturing methods have to be used for different combinations; for example, tape casting/powder metallurgy are used for specific matrixreinforcement types. The paper also describes the effect of various processing parameters on the morphology, interphase chemistry and thermal (both $k$ and CTE) of composites.

\section{Experimental procedure: materials and processing}

\subsection{Copper matrices}

Many techniques are used to manufacture powders. In the case of copper, generally either chemical or atomization methods are employed. Each technique plays a major part on final material properties, microstructure (grain size, distribution, morphology, and particle content), chemistry and finally, the cost of the powders.

Chemical methods can be used to prepare metallic powders; the difference between each is linked to the initial components and the chemical reaction. It is possible to use oxides, sulphates or carbonyl compounds which are reduced, precipitated or decomposed to obtain copper powders. Among these chemical methods, electrolysis which is a method using an electric current to drive the metallic ion reduction (Figure 2(a)) is promising (Saums, 2004). This type of powder will be used for the nonalloyed $\mathrm{Cu}$ matrices

Atomization refers to the process of breaking up metallic bulk liquids into fine droplets that solidify as powders (Saums, 2004). One can find various atomization processes depending on the break-up method used (pressure, spray, centrifugal, electrostatic, and ultrasonic). The most popular in the industry is the pressure atomization in which the metallic bulk liquid is broken up by the impact of a fluid under high pressure. Atomization produces spherical powders with various particle sizes, generally less than $150 \mu \mathrm{m}$ (Figure 2(b)). This type of powder will be used for the alloyed $\mathrm{Cu}$ matrices.

\subsection{Carbon reinforcements}

During the fabrication of the heat sink, our general goal is to optimize the thermomechanical properties of the composite material in terms of CTE and $k$. Towards this end, the metallic matrix (high CTE) is combined with carbon reinforcement with high $k$ and low CTE. The values of $k$ and CTE of the carbon fibers (CF), carbon nano fibers $(\mathrm{CNF})$ and diamond used are given in the results section and summarized in Table 1.
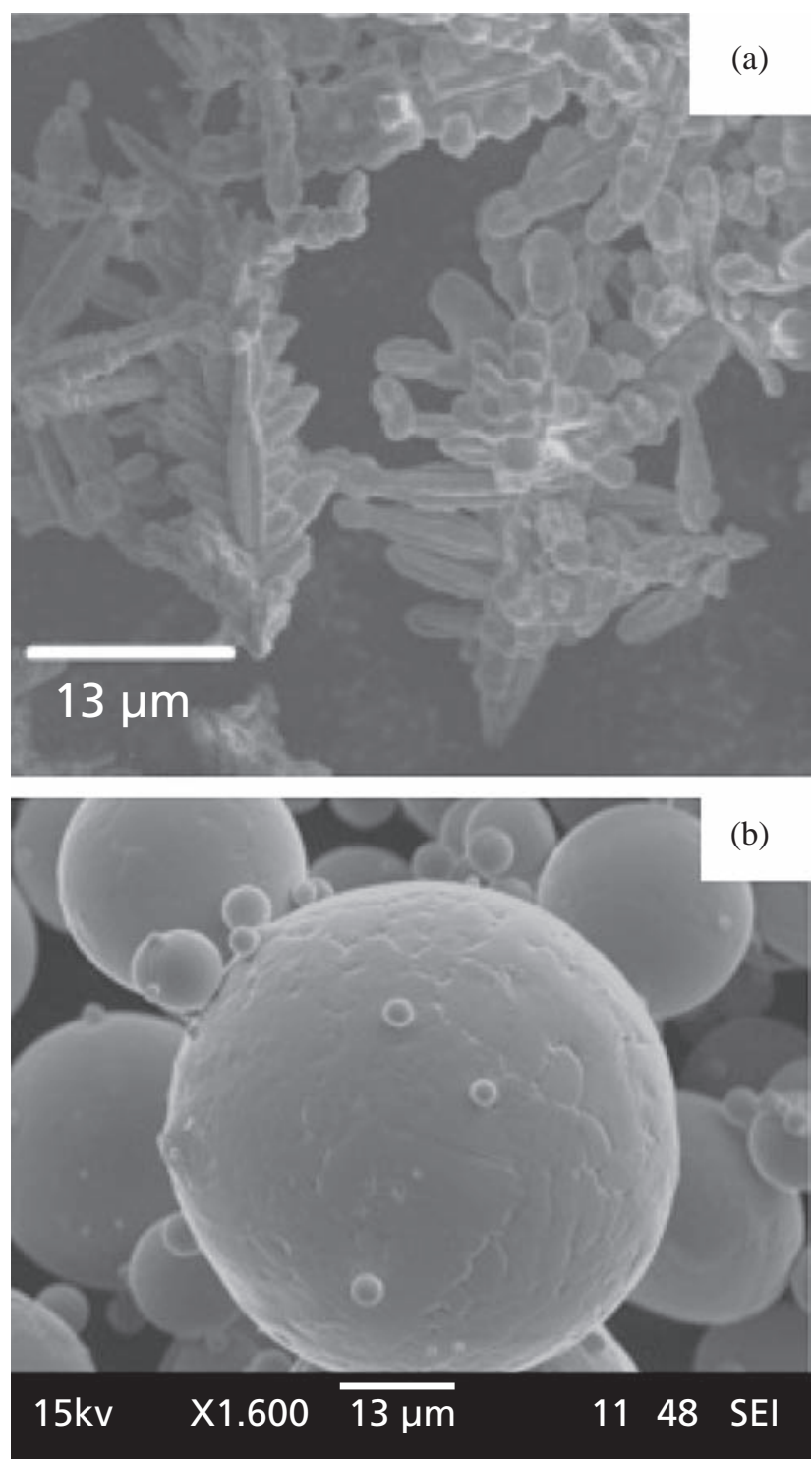

Figure 2. SEM micrographs of copper powder produced (a) by electrolysis and (b) by atomization.

\subsection{Heat sink fabrication}

MMC fabrication processes are numerous; therefore, we will just discuss the process relevant to heat sink fabrication. It is necessary to sinter materials with a high density (porosity $<4 \%$ ) to obtain high thermal conductivity. Indeed, the gas (air, argon ...) in the porosities is a thermal insulator and can strongly affect the thermal conductivity of the material. Fabrication processes of heat sinks can be classified in two groups: liquid route and solid route. The solid-route process is a powder metallurgy process, that is, the powder of metal matrix is mixed to the particle or short fiber reinforcement. This mix is then sintered in solid state. There are various powder-metallurgy processes that can be distinguished by the method of use to produce the 


\begin{tabular}{|c|c|c|c|c|c|}
\hline Material & & & Density & $\begin{array}{c}k \\
(W / m / K)\end{array}$ & CTE $\left(10^{-6} / \mathrm{K}\right)$ \\
\hline \multirow{3}{*}{ Matrices } & \multirow{3}{*}{\multicolumn{2}{|c|}{$\begin{array}{l}\mathrm{Cu} \\
\mathrm{Cu}-\mathrm{Cr} \\
\mathrm{Cu}-\mathrm{B}\end{array}$}} & 8.96 & 400 & 17 \\
\hline & & & 8.95 & 360 & 17 \\
\hline & & & 8.95 & 370 & 17 \\
\hline \multirow[t]{5}{*}{ Reinforcements } & \multirow{4}{*}{$\begin{array}{l}\text { Carbon fibers } \\
\text { (// CF axis / } \perp \text { CF axis) }\end{array}$} & K6371T & $2 \cdot 2$ & $140 / 10$ & $-1 / 12$ \\
\hline & & CN80C & $2 \cdot 2$ & $320 / 10$ & $-1 / 12$ \\
\hline & & K223HG & $2 \cdot 2$ & $540 / 10$ & $-1 / 12$ \\
\hline & & XN100 & $2 \cdot 2$ & $900 / 10$ & $-1 / 12$ \\
\hline & Diamond & & 3.5 & $800-2000$ & 1 \\
\hline
\end{tabular}

Table 1. Thermomechanical properties of matrices and reinforcements used.

loading. The conventional powder-metallurgy process consists in (a) shaping at ambient temperature and (b) strengthening the powder using at high temperature near the melting point. This last step is called sintering. This process does not allow obtaining composites with high density, which is why a pressure is usually applied during the sintering, referred to as hot-pressing processes (Bouvard, 2007). In the uniaxial hot pressing, a uniaxial pressure is applied at a temperature close to the melting point, which increases the density of the final composite (porosity $<5$ vol. $\%$ ). This technique allows producing composite materials with a high volume fraction of reinforcement (up to $50 \mathrm{vol} . \%$ ). Nevertheless, the mechanical resistance of the tool limits the maximum stress that can be applied. This process is widely used to fabricate MMC with aluminum or copper matrices because these metals are ductile even at low temperature.

\subsubsection{Tape-casting process}

Although the powder metallurgy process is convenient for threedimensional configurations or thick substrates ( $3 \mathrm{~mm}$ of thickness), tape-casting process works well for thin film (from 100 to 500 microns of thickness). The tape-casting process offers a novel solution for the processing of carbon-fiber reinforced copper matrix composites (Corbin et al., 1999). The main characteristics of this process are low cost, accurate control of the thickness (from 25 to $1000 \mu \mathrm{m}$ ), good surface finish and high quality of laminated materials (Geoffroy et al., 2007). One of the key points of the tape-casting process in the fabrication of copper/carbon composite sheets is the processing of stable slurry with copper particles and short carbon fibers. The tape-casting process consists of the preparation of a suspension of the inorganic powder(s) in an aqueous or nonaqueous system. This slurry is a complex multicomponent system typically containing the following components: powder (ceramic and/or metallic), solvent, dispersant, binder, and plasticizer. The suspension must be stable, homogeneous and with a suitable rheological behavior, according to the tape-casting process. The slurry is spread onto a support by means of a moving doctor blade. After evaporation of the solvent, the obtained dried tape, or green tape, is cut to the desired shape.

\section{Results and discussions}

\subsection{Copper/carbon fibers composites}

\subsubsection{Process}

Copper and carbon fibers pitch type, named K6371T and K223HG, usually form the starting powders (Table 1). Typical Scanning Electron Microscopy (SEM) observations show that copper particles are present with dendrite shapes with sizes ranging from 25 to $30 \mu \mathrm{m}$ (Figure 2(a)). Chopped carbon fibers have diameters ranging from 9 to $10 \mu \mathrm{m}$ and lengths between 100 to $300 \mu \mathrm{m}$. In the first step, copper powders and carbon fibers are mixed together. The mixed powder is then compacted in graphitic mould, which is heated by an induction system. The samples are pressed at $650^{\circ} \mathrm{C}$ under $50 \mathrm{MPa}$ for 20 minutes; the heating rate is $25^{\circ} \mathrm{C} / \mathrm{min}$. The temperature is controlled with a thermocouple inserted inside the mould. A vacuum in the chamber of 0.66 Pa prevents the oxidation of copper powder during the heating cycle. The final density of the composite material is close to $97 \%$ and no specific degradation of the carbon fiber is observed. The optical micrographs of the samples show a strong anisotropic structure (Figure 3), with an orientation of the carbon fiber perpendicular to the compaction direction. This anisotropy is caused by strains and stresses imposed by the processing-induced deformations and geometry, and will be reflected in the anisotropic thermal $(\mathrm{k})$ and thermomechanical (CTE) properties of the composite.

\subsubsection{Thermal properties}

Thermal conductivity $(\mathrm{k})$ and coefficient of thermal expansion (CTE) have been measured using a flash laser method and a horizontal dilatometer, respectively. Because of the anisotropic 
The role of controlled interfaces in the thermal management of copper-carbon composites Silvain et al.
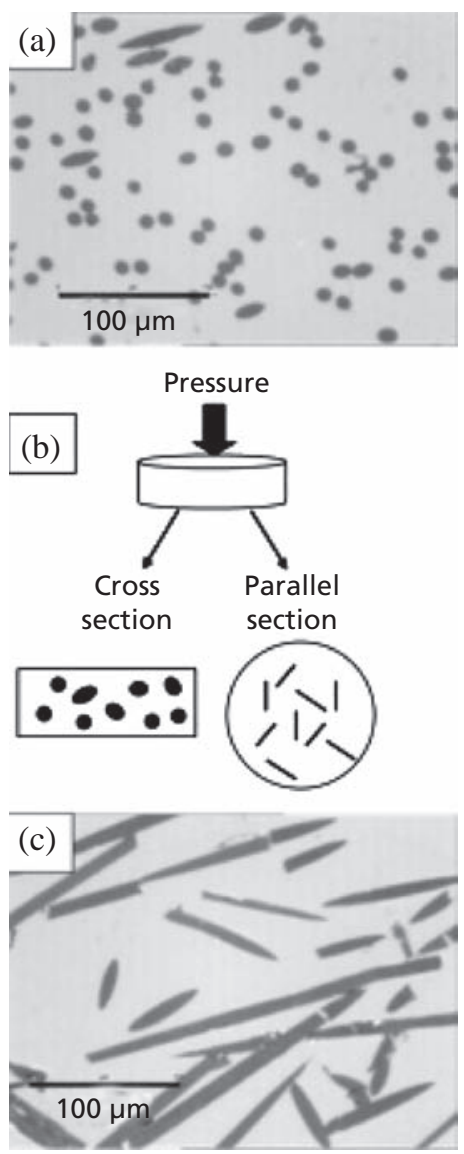

Figure 3. Optical micrographs of the composite material in (a) cross and (c) parallel section after densification and (b) schematic of the Carbon fiber orientation.

structure of the composite, these properties are determined in two perpendicular directions namely parallel to the pressing direction $\left(\mathrm{k}_{/ /}\right.$and $\left.\mathrm{CTE}_{\|}\right)$and perpendicular to the pressing direction $\left(\mathrm{k}_{\perp}\right.$ and $\mathrm{CTE}_{\perp}$ ). The $\mathrm{CTE}_{/ /}$of the composite are close to $1710^{-6} / \mathrm{K}$, whatever be the type and the volume fraction of carbon fibers used. In contrast, the $\mathrm{CTE}_{\perp}$ decreases when the carbon fibers volume fraction increases whatever be the fiber type used (Table 2). These anisotropic properties are because of the strong anisotropy of carbon fiber properties (Table 1) and their orientation perpendicular to the pressing direction in the composite.

Same anisotropy can be observed for the thermal conductivity measured on the various composites. Table 2 shows the evolution of $\mathrm{k}_{/ /}$and $\mathrm{k}_{\perp}$ for two types of carbon fibers (CF) with a volume fraction ranging from 30 to 40 vol. $\%$. This table shows that $\mathrm{k}_{/ /}$decreases when the carbon fiber volume fraction increases; $\mathrm{k}_{\| /}$is just linked to the $\mathrm{CF}$ volume fraction but not to the fiber type. However, the variation of $\mathrm{k}_{\perp}$ with the volume fraction is different; $\mathrm{k}_{\perp}$ is obviously linked to the carbon fiber volume fraction and also to their intrinsic thermal conductivity along their axis. Indeed, when the fibers used

\begin{tabular}{|c|c|c|c|c|}
\hline $\begin{array}{l}\text { Material } \\
\text { Cu/CF }\end{array}$ & $\begin{array}{c}6 \cdot 1 \cdot 1 \cdot 1 \text { CF } \\
\text { vol. } \%\end{array}$ & $\begin{array}{c}6 \cdot 1 \cdot 1 \cdot 2 \\
\text { Density }\end{array}$ & $\begin{array}{c}k \\
(W / m / K)\end{array}$ & $\begin{array}{c}6 \cdot 1 \cdot 1 \cdot 3 \mathrm{CTE} \\
\left(10^{-6} / \mathrm{K}\right)\end{array}$ \\
\hline \multirow{3}{*}{ Cu / K6371T } & 30 & $6 \cdot 8$ & $\begin{array}{l}300 \perp \\
180 / /\end{array}$ & 14 \\
\hline & 35 & $6 \cdot 5$ & $\begin{array}{l}330 \perp \\
160 / /\end{array}$ & 12 \\
\hline & 40 & $6 \cdot 2$ & $\begin{array}{l}360 \perp \\
140 / /\end{array}$ & 10 \\
\hline \multirow{3}{*}{$\mathrm{Cu} / \mathrm{K} 223 \mathrm{HG}$} & 30 & $6 \cdot 8$ & $\begin{array}{l}240 \perp \\
180 / /\end{array}$ & 14 \\
\hline & 35 & $6 \cdot 5$ & $\begin{array}{l}210 \perp \\
160 / /\end{array}$ & 12 \\
\hline & 40 & $6 \cdot 2$ & $\begin{array}{l}180 \perp \\
140 / /\end{array}$ & 10 \\
\hline
\end{tabular}

Table 2. Thermal conductivity parallel (//) and perpendicular $(\perp)$ to the pressing direction and CTE perpendicular $(\perp)$ to the pressing direction for copper/carbon fibers composites.

have a thermal conductivity along their axis greater than that of copper, $\mathrm{k}_{\perp}$ increase with the volume fraction (example of K223HG carbon fiber type). However, when the carbon fibers used have a thermal conductivity along their axis lower than that of copper, $\mathrm{k}_{\perp}$ decrease with the volume fraction (example of K6371T carbon fiber type).

\subsection{Copper/CNF composites}

\subsubsection{Salt-decomposition process}

In this process (Silvain et al., 2009; Vincent, 2008), after acid treatment, the functionalized CNF are suspended in ethanol and ultrasonically treated. Then, the copper salt (copper nitrate) is dissolved in the suspension containing the CNF. This suspension is mechanically stirred to achieve a good homogeneity while a constant temperature of $70^{\circ} \mathrm{C}$ is maintained. During this step, the solvent is evaporated and a blue powder consisting of CNF coated with $\mathrm{Cu}-(\mathrm{O}-\mathrm{N})$ phases is obtained. The mixture is then heat treated in air at $400^{\circ} \mathrm{C}$ for 2 hours to transform the $\mathrm{Cu}-\mathrm{O}-\mathrm{N}$ coating into copper oxide, as follows:

$$
\text { 1. } \mathrm{Cu}_{2}(\mathrm{OH})_{3}\left(\mathrm{NO}_{3}\right)(\mathrm{s}) \rightarrow 2 \mathrm{Cu}(\mathrm{OH})_{2}(\mathrm{~s})+\mathrm{NO}_{2}(\mathrm{~g})
$$

and at

$$
\begin{array}{ll}
\text { 2. } & \mathrm{T}=423 \mathrm{~K} \\
\mathrm{Cu}(\mathrm{OH})_{2}(\mathrm{~s}) \rightarrow \mathrm{CuO}(\mathrm{s})+\mathrm{H}_{2} \mathrm{O}(\mathrm{g})
\end{array}
$$


The mixture is then reduced under $\mathrm{Ar} / \mathrm{H}_{2}$ at $400^{\circ} \mathrm{C}$ for 1 hour to transform the copper oxide into metallic copper. Subsequently, $\mathrm{CNF} / \mathrm{Cu}$ nano composites are fully sintered by hot pressing at $650^{\circ} \mathrm{C}$ under $50 \mathrm{MPa}$ for 20 minutes with a heating rate of $25^{\circ} \mathrm{C} /$ $\mathrm{min}$. Sintering is performed under vacuum to prevent oxidation of the copper powder during the heating cycle.

\subsubsection{Microstructure}

Typical transmission electron microscopy (TEM) micrographs of densified $\mathrm{Cu} / \mathrm{CNF}$ materials are shown in Figure 4. It can be seen from this figure, that porosity is absent and there is no delamination at the matrix/reinforcement interface. Further, $\mathrm{Cu} /$ CNF interface is very sharp with a high density of dislocation inside the $\mathrm{Cu}$ matrix and close to the CNF. Silvain et al. (2009) have shown that dislocations occur due to the thermal stresses induced at the interface of fiber-matrix with large differential CTE. It is postulated in their work that the different families of dislocations act to reduce the different types of stresses, (e.g. shear, normal) and act to prevent delamination at the interfaces. In this figure, we can observe higher density of dislocations in the copper matrix induced due to the large differential CTE between $\mathrm{CNF}$ and $\mathrm{Cu}\left(\mathrm{Cu}\right.$ matrix $\left(17 \cdot 10^{-6} /{ }^{\circ} \mathrm{C}\right)$ and the $\mathrm{CNF}\left(-1 \cdot 10^{-6} /{ }^{\circ} \mathrm{C}\right.$ parallel to the main axis of the carbon fibers and $10 \cdot 10^{-6} /{ }^{\circ} \mathrm{C}$ perpendicular to their main axis). Absence of delamination and the presence of dislocations indicate that not only the thermal stresses are large but also the interface is strong. This strong interface is the result of the strong chemical bond through the surface-modified oxygen.

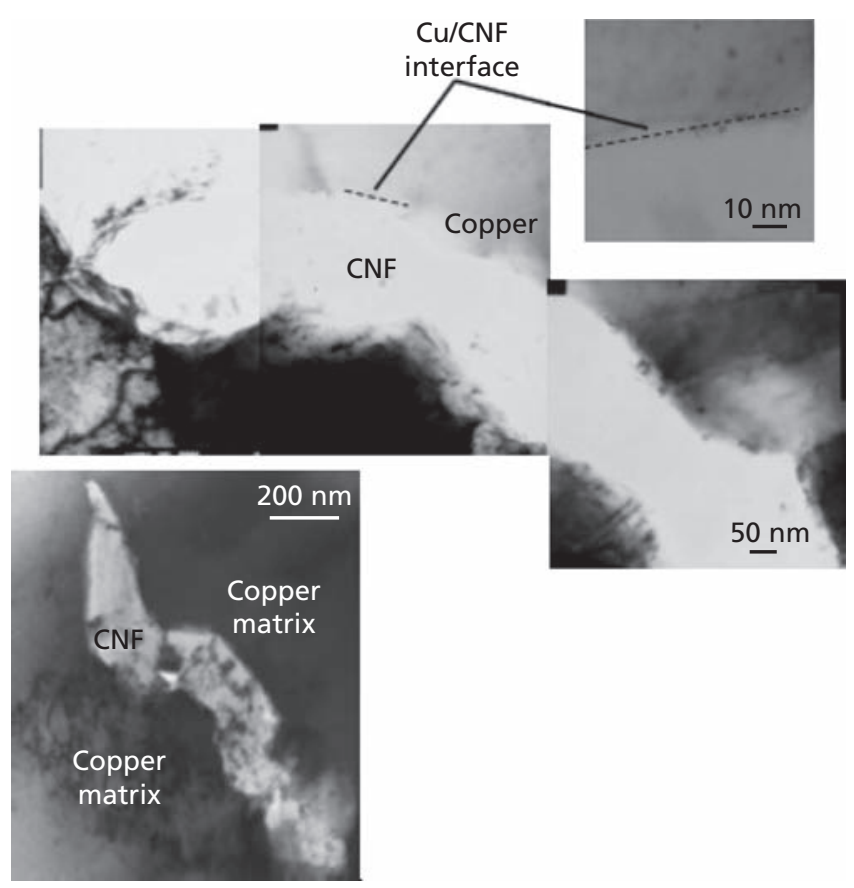

Figure 4. TEM micrographs of densified CU/CNF composite material.

\subsubsection{Thermal conductivity}

Figure 5 presents the variation of the thermal conductivity with volume fraction of CNF. In this figure, there are two horizontal regimes between $0 \%$ and $5 \%$ and then from $5 \%$ to $10 \%$. It should be observed that the $5 \%$ to $10 \%$ regime is above the conductivity line for that of copper. It should be noted that our goal is to achieve conductivity higher than that of copper. Thermal conductivity in CNF-organic composites a value greater that of copper was achieved. The work shows that in the case of salt decomposition-based PM, between the ranges of $5 \%-10 \%, \mathrm{Cu} / \mathrm{CNF}$ composites yield such uniqueness. In our opinion, three important factors can affect the conductivity of $\mathrm{Cu} / \mathrm{CNF}$ composites. The first is the distribution of the reinforcement within the matrix, the second is the nature of the interfaces, and the third is the level of porosity. Based on SEM and TEM studies, good dispersion of fibers can be observed in the PM with salt-deposition process. Further TEM studies confirm that there is a strong interface as evidenced by the lack of delamination and the presence of dislocation activity. The porosity is at a very low value of about $1 \%$ and remains low up to fiber volume fraction of 20\% (Silvain et al., 2009; Vincent, 2008).

\subsection{Copper alloys/carbon fibers and copper alloys/diamond composites}

\subsubsection{Material and densification process}

The major problem in the development of the $\mathrm{Cu} / \mathrm{CF}$ and $\mathrm{Cu} /$ diamond (D) composites is the absence of chemical reaction between copper and carbon. Indeed, after several thermal cycles, the initial mechanical bonding (induced by the CTE mismatch between copper and carbon, after cooling) may be degraded, thus leading to a weak interface and a inefficient transfer of properties between the matrix and the reinforcement (Veillère, 2009; Veillère et al., 2011a, 2011b). To solve this problem, an alloying element (chromium or boron) is added to the copper matrix to obtain a strong chemical interface, after diffusion. The copper-base alloys are $\mathrm{Cu}-\mathrm{Cr}(0.63$ wt.\% of $\mathrm{Cr})$ and $\mathrm{Cu}-\mathrm{B}(0.05$ wt. $\%$ of $\mathrm{B})$. The powder is prepared by CERAM (United Kingdom), by an atomization process, with

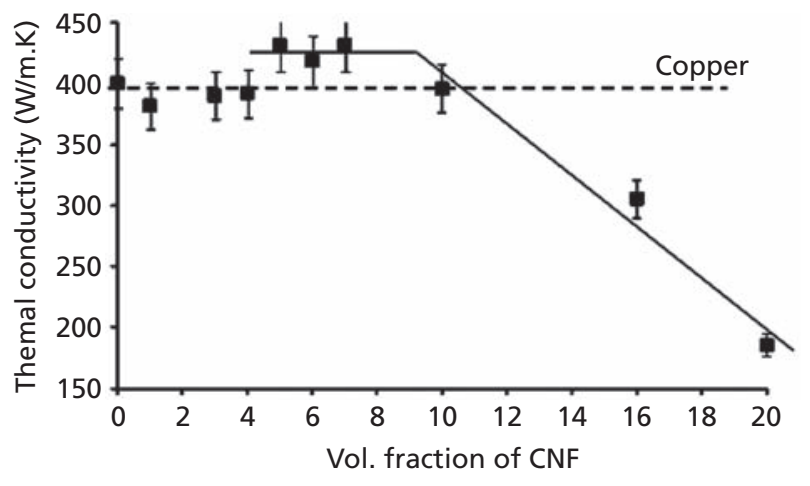

Figure 5. Variation of the thermal conductivity of the $\mathrm{Cu} / \mathrm{CNF}$ composite with the volume fraction of CNF. 
a particle size under $25 \mu \mathrm{m}$. Two kinds of chopped carbon fibers (CN80C and XN100), manufactured by Nippon Graphite Fiber Corporation, are investigated in that work. The properties of these carbon fibers are given in Table 1 . The difference between these two kinds of carbon fibers is their thermal conductivity values along their axis. The diamond powders are diamond quality grade MBD6 which are faceted with hexagonal or octahedral shapes and diameters between 40 and $50 \mu \mathrm{m}$.

Copper alloy powders are mechanically mixed with the reinforcement and are then uniaxially hot pressed at $950^{\circ} \mathrm{C}$ under 50 MPa for 20 minutes to obtain dense materials. During the sintering cycle, a reducing atmosphere of Argon/Hydrogen (5 vol. \%) is used to first deoxidize the initial $\mathrm{Cu}$ alloys powder and then prevent the oxidation of the copper. An optimized annealing treatment is then performed $\left(1000^{\circ} \mathrm{C}, 24\right.$ hours, under reducing atmosphere) on the most promising composite $(\mathrm{Cu}-\mathrm{Cr} / \mathrm{CN} 80 \mathrm{C})$ to increase the diffusion of the alloying element $(\mathrm{Cr})$ toward the $\mathrm{Cu} / \mathrm{CF}$ interface and, therefore, create strong carbide interface bonds.

\subsubsection{Chemical and microstructural characterizations}

To characterize the distribution of the alloying element in the composite as a function of the annealing treatment, an electron probe microanalysis (EPMA) of $\mathrm{Cu}-\mathrm{Cr} / \mathrm{CF}$ composite materials has been performed (Figure 6). It was observed that the copper matrix is almost free of chromium, which has diffused toward the copper/carbon interface. On this mapping, the nonuniformity of the interphase with a higher segregation of chromium on the carbon fiber tip was also observed. The tip segregation is because of the $\mathrm{sp}^{3}$ carbon present in these areas which favor the formation of carbide.

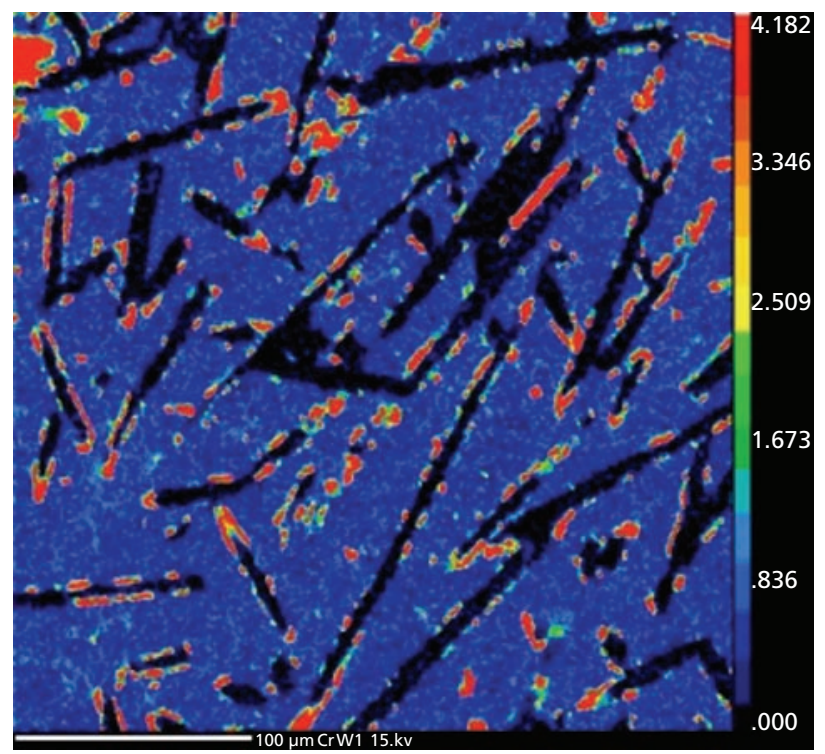

Figure 6. EPMA mapping of the Chromium in Cu-Cr/CF composite.
An Auger electron spectroscopy (AES) line profile has been obtained across a copper/carbon fiber interphase. One representative line profile is shown in Figure 7. Atomic concentrations of copper, carbon and chromium are measured, along the line profile. A deconvolution of the carbon peak has been applied to distinguish the carbon from the chromium carbide ( $\mathrm{C}-\mathrm{Cr}$ bonds) and the free carbon (C-C bonds). This deconvolution process has been performed with two reference profiles: one for the free carbon $(\mathrm{C}-\mathrm{C})$ and one for the carbon inside the $\mathrm{Cr}_{2} \mathrm{C}_{3}$ chromium carbide $(\mathrm{C}-\mathrm{Cr}$ ). The figure shows three distinct zones: the matrix, the interphase and the fiber. Both chromium and $\mathrm{C}-\mathrm{Cr}$ carbon are present only in the interphase. This analysis confirms the segregation of chromium in the form of chromium carbide at the copper/carbon fiber interface. The thickness of the interphase ranges between $0 \cdot 1$ to 1 micrometers. Figure 8 (a) shows a TEM micrograph of a selected region of an interphase, where the carbon fiber is on the right, the copper matrix on the left and the interphase in-between. The HRTEM micrograph of the circled zone is given in Figure 8(b). Figure $8 \mathrm{c}$ is the diffraction pattern in each phase. The index of the diffraction pattern in the matrix (Figure $8(\mathrm{c}-1)$ ) clearly identifies a crystal of copper with a $\{220\}$ zone axis. Figure 8(c-3) shows that carbon exists in both crystalline and amorphous forms and the crystals are aligned along the fiber orientation. The diffraction pattern in the interphase region (Figure 8(c-2)) shows the presence of $\mathrm{Cr}_{3} \mathrm{C}_{2}$. In Figure 8b, the interphase appears to be polycrystalline with distinguishable (sub) grain boundaries.

\subsubsection{Thermal properties}

- Copper/carbon fibers composites

Table 3 presents the values of thermal conductivity, CTE and density of $\mathrm{Cu} / \mathrm{CF}$ and $\mathrm{Cu}-\mathrm{X} / \mathrm{CF}$ composites (with $\mathrm{X}=\mathrm{Cr}, \mathrm{B}$ ). Thermal diffusivity is measured along the pressure direction of the densification process.

As explained previously, for $\mathrm{Cu} / \mathrm{CF}$ composites, this densification process induces an anisotropic structure in the samples with a

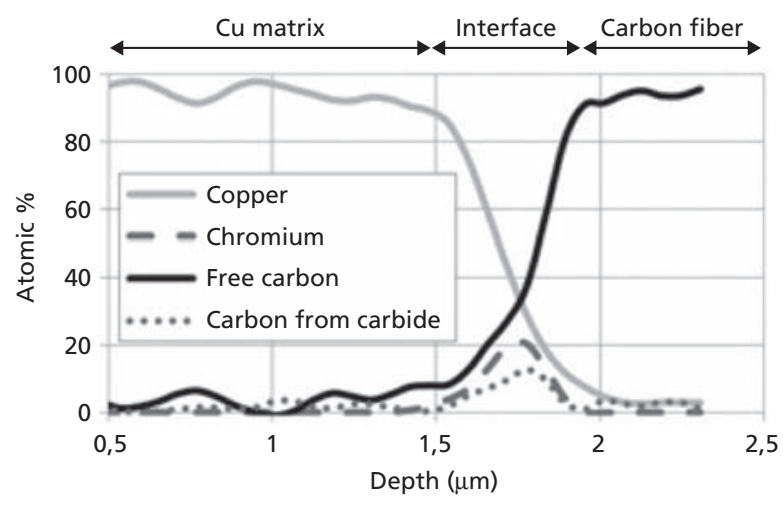

Figure 7. AES line profile through the CU/CF fiber interface on a Cu-Cr/CF composite. 

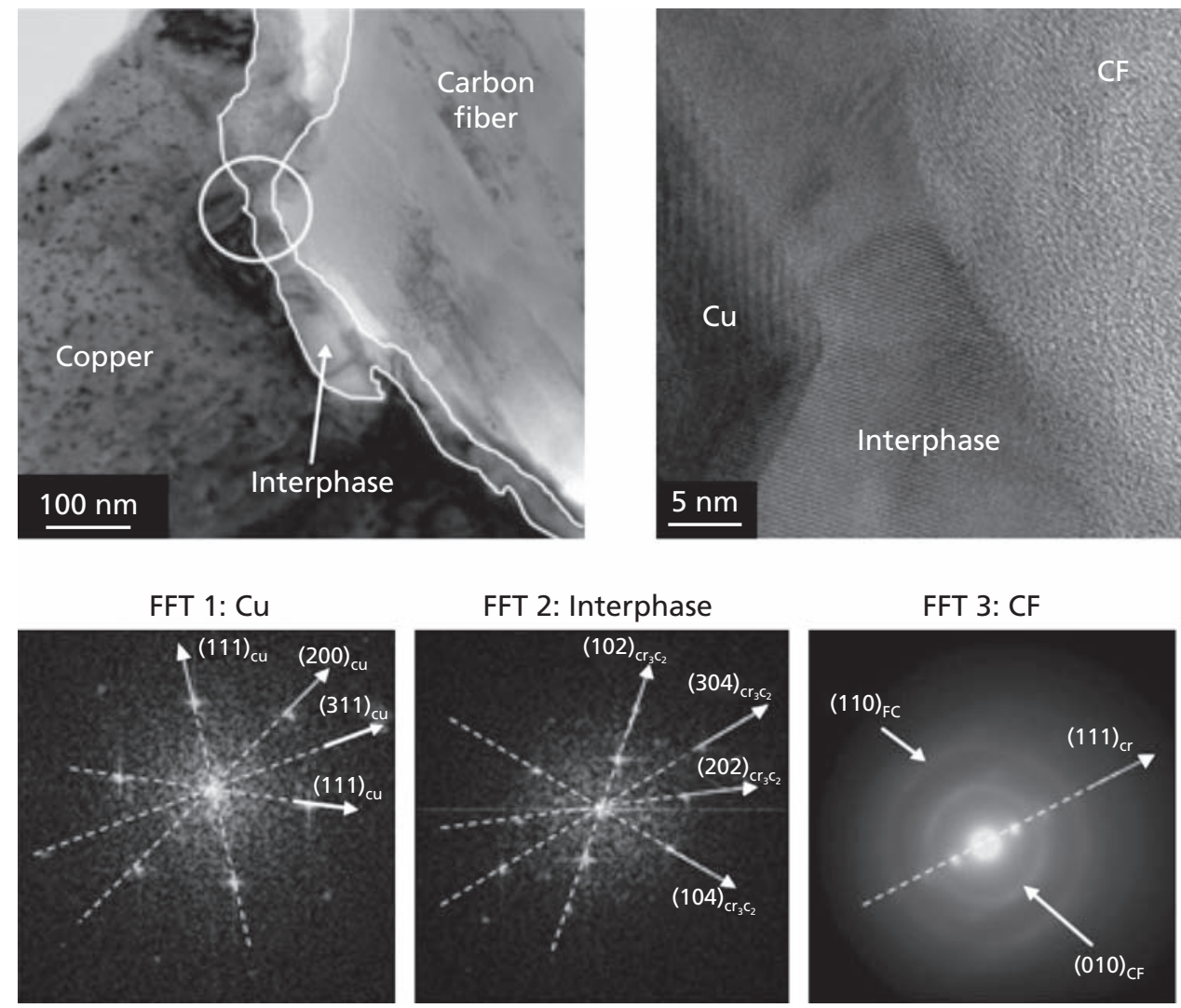

FFT 2: Interphase

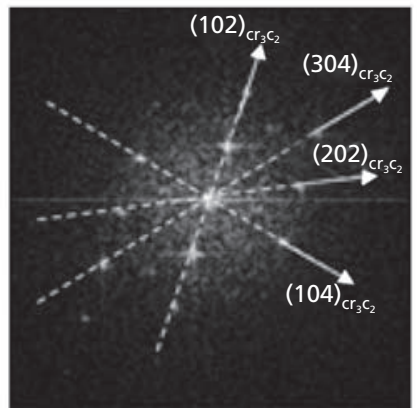

FFT 3: CF

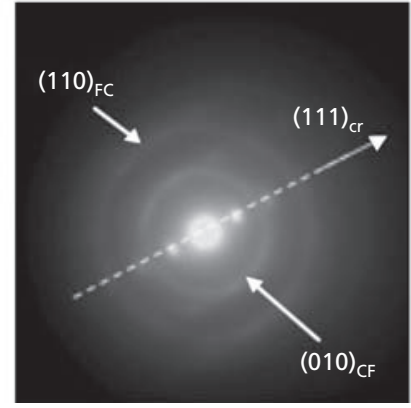

Figure 8. TEM micrographs (a) of the copper-chromium/carbon fiber composite material after annealing treatment, (b) magnification of the circled area in (a) and (c) diffraction pattern inside the copper, the interphase and the carbon fiber.

preferential orientation of the carbon fibers perpendicular to the pressure axis. Therefore, the measure corresponds to the diffusivity perpendicular to the fiber axis. Because of the low transverse thermal conductivity of the fiber $(10 \mathrm{~W} / \mathrm{m} / \mathrm{K})$, it should be noted that we measured the lowest thermal diffusivity of our composite material. Measurements are done for both $\mathrm{Cu}-\mathrm{X} / \mathrm{CN} 80 \mathrm{C}$ and $\mathrm{Cu}-\mathrm{X} /$ XN100 composites. The calculated thermal conductivities from the experimental thermal diffusivities are shown in Table 3 . The composite materials with the XN100 fibers have higher thermal conductivity than those with the CN80C fibers. However, it should be noted that both carbon fibers have the similar thermal conductivity in the normal direction, but different thermal conductivity along their axis (Table 1). The difference of thermal conductivity measured between these two sets of composite materials can be explained by the orientation of the carbon fiber inside the matrix. Indeed, if the carbon fibers are not aligned perfectly normal but at a slight angle, then that difference in the orientation will lead to a contribution to thermal conductivity in parallel direction.

CTE measured along the carbon fiber axis for each sample are also shown in Table 3. An improvement of the CTE for the $\mathrm{Cu}-\mathrm{X} /$

\begin{tabular}{|c|c|c|c|}
\hline Matrix & Reinforcement & $\begin{array}{c}k_{/ /} \\
(\mathrm{W} / \mathrm{m} / \mathrm{K})\end{array}$ & $\mathrm{CTE}_{\perp}\left(10^{-6} / \mathrm{K}\right)$ \\
\hline \multirow{3}{*}{$\mathrm{Cu}$} & - & 400 & 17 \\
\hline & CN80C & 180 & 14 \\
\hline & XN100 & 220 & 14 \\
\hline \multirow{3}{*}{$\mathrm{Cu}-\mathrm{Cr}$} & - & 360 & 17 \\
\hline & CN80C & 180 & 12 \\
\hline & XN100 & 190 & 14 \\
\hline \multirow{3}{*}{ Cu-B } & - & 370 & 17 \\
\hline & CN80C & 180 & 12 \\
\hline & XN100 & 230 & 13 \\
\hline
\end{tabular}

Table 3. Thermal conductivity parallel (//) to the pressing direction and CTE perpendicular $(\perp)$ to the pressing direction for copper alloys/ carbon fibers composites with a volume fraction of $30 \%$. 
Emerging Materials Research Volume 1 Issue EMR2
The role of controlled interfaces in

the thermal management of copper-carbon composites

Silvain et al.
$\mathrm{CF}$ composites, compared to the $\mathrm{Cu} / \mathrm{CF}$ reference was observed. The high temperature $\left(950^{\circ} \mathrm{C}\right)$ of the densification process has promoted the diffusion of a small part of the alloying element at the $\mathrm{Cu} / \mathrm{CF}$ interface. This reinforces the bond between the copper and the carbon and thus increases the thermomechanical properties of the composite. Better results for the CTE are observed with the CN80C fibers, which are those with the lower thermal conductivity $(320 \mathrm{~W} / \mathrm{m} / \mathrm{K})$. Because thermal conductivity is linked to the graphitic plane arrangement in the carbon fiber, a lower value in the case of the CN80C fibers implies more defects in plane alignment, and thus more nucleation sites at the fiber surface. This hypothesis can be confirmed by the Raman spectroscopy analyses performed on both the carbon fibers. Indeed this technique allows quantification of the Graphite defects in the carbon fiber by examining the intensity ratio of the $\mathrm{G}$ band and the D band $\left(\mathrm{I}_{\mathrm{G}} / \mathrm{I}_{\mathrm{D}}\right)$ of the graphite in the Raman spectrum. The results were an $I_{G} / I_{D}$ ratio of 4.5 and 7.3 for the $C N 80 C$ and XN100 carbon fibers, respectively. Therefore, these analyses confirm that the quantity of defects is higher in the CN80C than in the XN100 carbon fibers.

\section{- Copper/diamond composite}

The thermal conductivity of the $\mathrm{Cu}-\mathrm{X} / \mathrm{D}$ composites is given in Figure 9. This figure shows the evolution of the thermal conductivity versus the volume fraction of diamond for both $\mathrm{Cu}-\mathrm{Cr} / \mathrm{D}$ and $\mathrm{Cu}-\mathrm{B} / \mathrm{D}$ composites. the same behavior for both composites; when the diamond fraction increases, the thermal conductivity increases until 30 vol.\% of diamond and then decreases sharply for $40 \mathrm{vol}$. $\%$. This change is linked to the decrease in density of the composite from $97 \%$ to $91 \%-93 \%$. Indeed, increasing diamond contents creates diamond-diamond contacts and generates porosities in the composite. Nevertheless, it should be noted that the addition of only 10 vol. \% of diamond in both matrices produces a composite with a thermal conductivity higher than that of copper $(400 \mathrm{~W} / \mathrm{m} / \mathrm{K})$. Concerning the alloying elements (boron or chromium) used in the

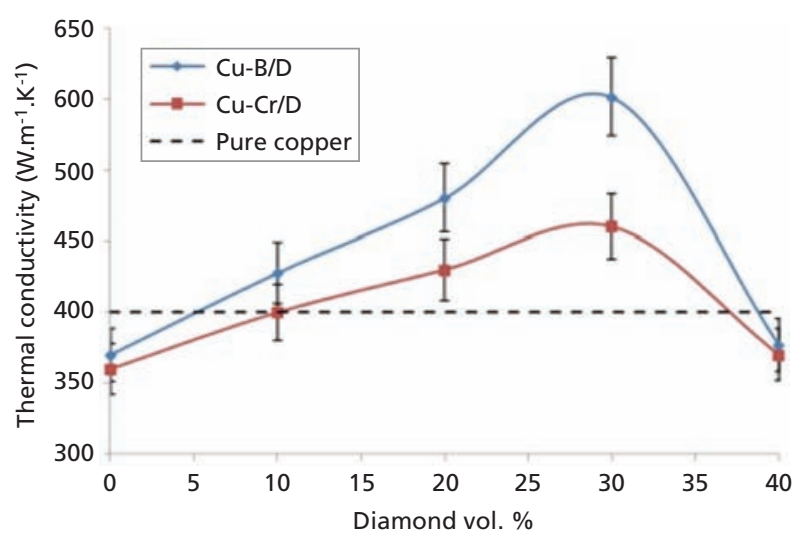

Figure 9. Variation of the thermal conductivity of the $\mathrm{Cu}-\mathrm{B} / \mathrm{D}$ and $\mathrm{Cu}-\mathrm{Cr} / \mathrm{D}$ composites with the volume fraction of diamond. copper matrix, it is clear that boron has a greater influence than chromium on the composite thermal conductivity.

\subsection{Copper diamond composite with optimized interface fabricated by tape-casting process}

\subsubsection{Material and process}

Diamond has exceptional thermal properties with the highest thermal conductivity at room temperature of all known materials $(\lambda=[800-2000] \mathrm{W} / \mathrm{m} / \mathrm{K})$. However, its very low CTE $(\alpha=1 \cdot 0$ $\times 10^{-6} /{ }^{\circ} \mathrm{C}$ ) remains to be a problem. Thus, it is interesting to consider the use of diamond as reinforcements embedded in a thermal package substrate, such as a copper matrix $(\mathrm{Cu})$. In this study, $\mathrm{Cu} / \mathrm{D}$ composite films were fabricated by tape casting and hot pressing. Diamond powders from Henan Zhongxin Co., China, and dendritic copper powder from Ecka Poudmet, Germany, were used to process the $\mathrm{Cu} / \mathrm{D}$ composites. After tape casting, the $\mathrm{Cu} / \mathrm{D}$ composite tapes are first heat treated at $400^{\circ} \mathrm{C}$ under air for 2 hours (debinding treatment), then heat treated 60 minutes at $400^{\circ} \mathrm{C}$ under $\mathrm{Ar} / \mathrm{H}_{2}$ (reducing treatment). Finally, after stacking of 10 to 15 tapes, the $\mathrm{Cu} / \mathrm{D}$ composites were hot pressed during 20 minutes at $650^{\circ} \mathrm{C}$ under $50 \mathrm{MPa}$ to obtain dense materials.

\subsubsection{Copper particles deposition onto diamond powders} $\mathrm{Cu} / \mathrm{D}$ composites fabricated by powder metallurgy have demonstrated to feature weak interfacial bonding because pure liquid copper does not wet diamond particles. The nonreactive $\mathrm{Cu} / \mathrm{D}$ interface is critically detrimental to the thermal properties of the $\mathrm{Cu} / \mathrm{D}$ composites. Carbide-forming materials, namely chromium or boron, are usually employed to bond diamond reinforcements to the copper matrix, either by being alloyed to the matrix (Schubert et al., 2008; Weber and Tavangar, 2007) or by being directly coated onto diamonds (Xia et al., 2009). However, the carbide interphase also acts as a thermal barrier and affects the heat transfer between electronic conduction in copper and phonic conduction in diamond. Here, an innovative process that consists in depositing copper nanoparticles onto diamond reinforcements through $\mathrm{C}-\mathrm{O}-\mathrm{P}-\mathrm{O}-\mathrm{Cu}$ and/or C-P-O-Cu bonds prior to sintering to create strong chemical bonding between the diamonds and the copper matrix was used (Silvain et al., 2010). This process leads to dense and cohesive $\mathrm{Cu} / \mathrm{D}$ composites without using carbideforming elements, thereby allowing high thermal performances with minimum diamond content making these $\mathrm{Cu} / \mathrm{D}$ composites highly cost effective.

Figure 10 shows diamond particle covered by copper particles of submicron size. One can see that the coverage of the diamond surface by the copper particles is remarkably uniform. In addition, the size of the surface $\mathrm{Cu}$ particles can be adjusted depending on the reduction time and temperature, as shown on Figure 10(a) and Figure 10(b) with $\mathrm{Cu}$ particle sizes ranging from $400 \mathrm{~nm}$ to $1 \mu \mathrm{m}$ (after 60 minutes at $400^{\circ} \mathrm{C}$ under $\mathrm{Ar} / \mathrm{H}_{2}$ ), on Figure $10(\mathrm{c})$ with $\mathrm{Cu}$ particles sizes ranging from 300 to $800 \mathrm{~nm}$ (after 1 minute at $400^{\circ} \mathrm{C}$ 
Emerging Materials Research

Volume 1 Issue EMR2
The role of controlled interfaces in

the thermal management of

copper-carbon composites

Silvain et al.
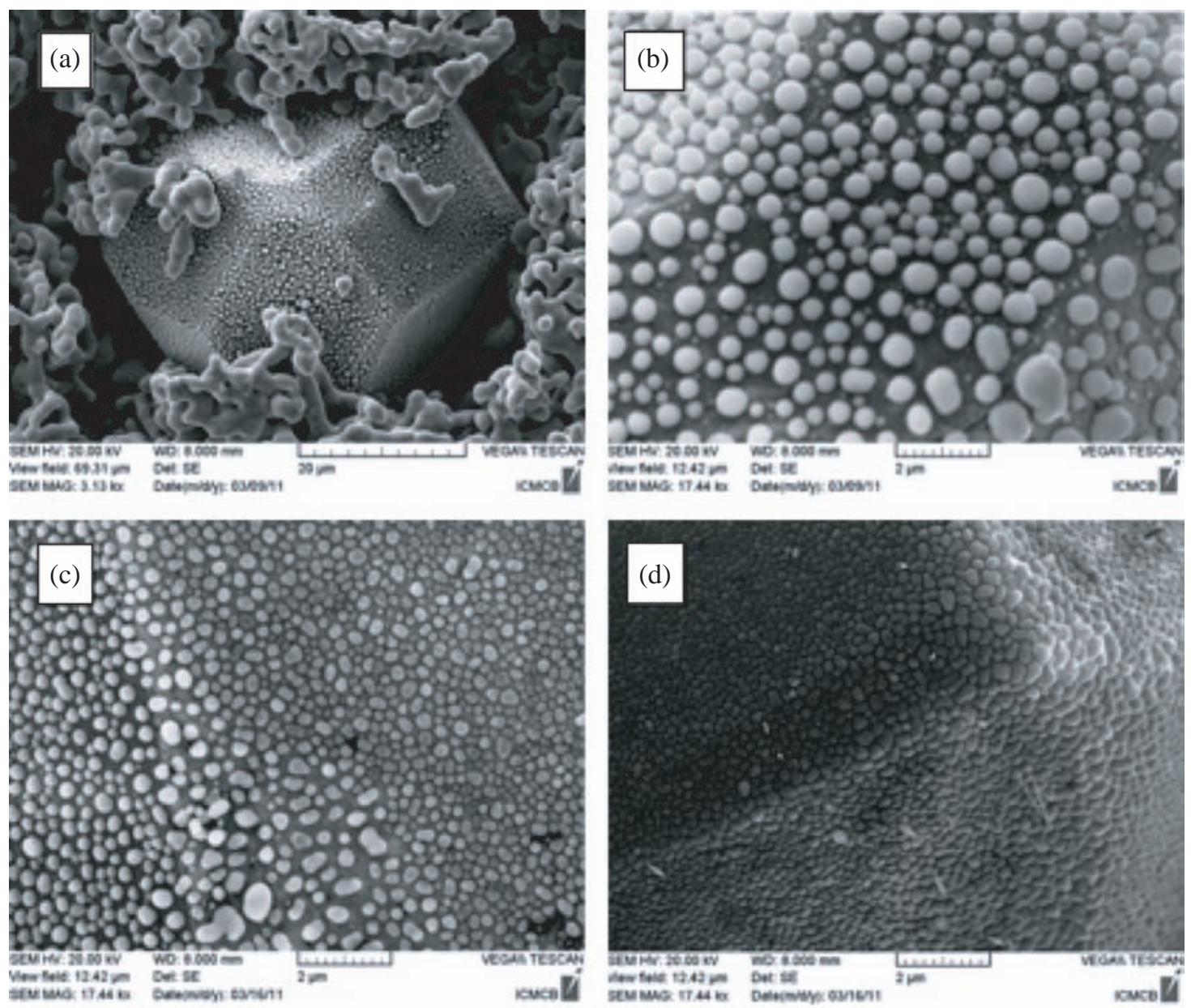

Figure 10. SEM micrographs of diamond reinforcements coated with copper particles: $(\mathrm{a}, \mathrm{b})$ after 60 minutes under $\mathrm{Ar} / \mathrm{H}_{2}$ at $400^{\circ} \mathrm{C}$ (c) after 1 minute under $\mathrm{Ar} / \mathrm{H}_{2}$ at $400^{\circ} \mathrm{C}$ (d) after 1 minute under $\mathrm{Ar} / \mathrm{H}_{2}$ at $350^{\circ} \mathrm{C}$. under $\mathrm{Ar} / \mathrm{H}_{2}$ ) and Figure $10(\mathrm{~d})$ with $\mathrm{Cu}$ particle sizes ranging from $100 \mathrm{~nm}$ to $400 \mathrm{~nm}$ (after 1 minute at $350^{\circ} \mathrm{C}$ under $\mathrm{Ar} / \mathrm{H}_{2}$ ). However, the influence of the size of the $\mathrm{Cu}$ nanoparticles coating on the final thermal properties of the composites is not yet clear. Regarding the chemical process responsible for the $\mathrm{Cu}$ particles deposition, XPS analysis has demonstrated that the mixing of the dispersant agent (CP213, phosphate ester) with the powders during formulation leads to the creation of phosphorus-functionalized nucleation sites on the diamond powder surface. During debinding, copper powders are oxidized and wire-shaped $\mathrm{CuO}$ nanostructures are observed to grow on the copper dendrites. Such $\mathrm{CuO}$ nanowires growth process has been reported in previous studies (Jiangs et al., 2002). During the reduction treatment, copper sublimed from $\mathrm{CuO}$ nanowires and settles again onto the chemically active sites on the diamond particle surface through $\mathrm{C}-\mathrm{O}-\mathrm{P}-\mathrm{O}-\mathrm{Cu}$ and/or $\mathrm{C}-\mathrm{P}-\mathrm{O}-\mathrm{Cu}$ chemical bridges. During the hot pressing step, $\mathrm{Cu}-\mathrm{Cu}$ metallic bonds are formed between the $\mathrm{Cu}$ nanoparticles onto the diamonds and the copper particles that will form the $\mathrm{Cu}$ matrix after densification. The $\mathrm{Cu}$ nanoparticles thus enable the formation of a cohesive interface between the copper matrix and the diamond reinforcements through strong chemical bonding without requiring any carbide-forming materials.

\subsubsection{Thermal properties}

As shown on Figure 11, the average thermal conductivity of multilayer composite materials, fabricated by tape-casting process, increases from 320 to $460 \mathrm{~W} / \mathrm{m} / \mathrm{K}$ with respect to diamond volume fractions ranging from $0 \%$ to $40 \%$. This confirms that the copper particles deposited onto the diamond reinforcements prior to sintering effectively act as bonding agents between diamond and the copper matrix, enabling efficient interfacial heat transfer between electronic and phonic conductions. However, a drop of thermal conductivity to $313 \mathrm{~W} / \mathrm{m} / \mathrm{K}$ with a diamond volume fraction of $50 \%$ because of the low compaction of the $\mathrm{Cu}_{50} \mathrm{D}_{50}$ 
Emerging Materials Research Volume 1 Issue EMR2
The role of controlled interfaces in

the thermal management of copper-carbon composites

Silvain et al. composite, which is detrimental to the thermal conductivity was observed. This decrease in thermal conductivity means that the percolation threshold (i.e. the reinforcement volume fraction at which a continuous path between reinforcements exists in the composite) has reached. The percolation threshold occurs between $40 \%$ and $50 \%$ in diamond volume fraction. A maximum thermal conductivity of $460 \mathrm{~W} / \mathrm{m} / \mathrm{K}$ with a diamond volume fraction of 40 $\%$, which is a significant improvement compared to pure copper $\left(\lambda_{\mathrm{Cu}}=400 \mathrm{~W} / \mathrm{m} / \mathrm{K}\right)$ was observed. An improvement in this result in our ongoing effort using single tape systems is expected.

As shown on Figure 12, the averages measured CTEs of composites decrease linearly from $18.9 \times 10^{-6} /{ }^{\circ} \mathrm{C}$ to $11.8 \times 10^{-6} /{ }^{\circ} \mathrm{C}$ with diamond volume fractions ranging from $0 \%$ to $50 \%$ and evolve with the same slope as the theoretical values. Unlike thermal conductivity, CTE is not affected by the low compaction exhibited by the $\mathrm{Cu}_{50} \mathrm{D}_{50}$ composites as it keeps decreasing between $40 \%$ and $50 \%$, although its decrease is less pronounced between these two volume fractions. The CTE of pure copper samples fabricated by tape casting and hot pressing is measured to be $18.9 \times 10^{-6} /{ }^{\circ} \mathrm{C}$, which is higher than the theoretical value $\left(\mathrm{CTE}_{\mathrm{Cu}}=17 \times 10^{-6} /{ }^{\circ} \mathrm{C}\right)$. This also can be ascribed to the fact that our samples are multilayered systems,

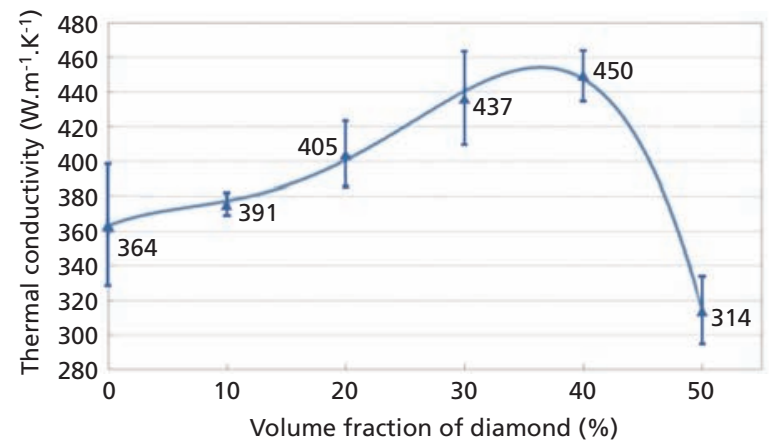

Figure 11. Experimental thermal conductivity of the diamond reinforced copper matrix composites as a function of diamond volume fraction.

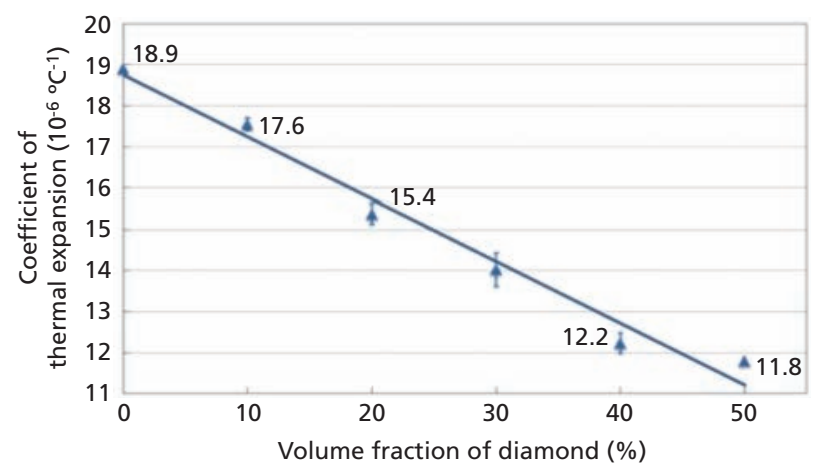

Figure 12. Experimental CTEs of the diamond reinforced copper matrix composites as a function of diamond volume fraction. instead of single tapes. The interfaces between tapes may degrade the thermomechanical properties of stack. A minimum CTE of 11.8 $\times 10^{-6} /{ }^{\circ} \mathrm{C}$ with a diamond volume fraction of $50 \%$ is reached, which represents a strong improvement towards our goal to the CTE of $\mathrm{Si}$ of $4 \times 10^{-6} /{ }^{\circ} \mathrm{C}$ compared to the $\mathrm{CTE}$ of pure copper $\left(\mathrm{CTE}_{\mathrm{Cu}}=17\right.$ $\times 10^{-6} /{ }^{\circ} \mathrm{C}$ ). These results demonstrate that the copper deposition process leads to a strong interfacial bonding enabling an efficient thermal expansion load transfer at the matrix/reinforcement interface.

\section{Conclusions}

In electronic packaging applications, such as thermal heat sink in computers, there is a growing and immediate need to design materials with high thermal conductivity and specified thermalexpansion characteristics. As copper is the reference material of choice, adding carbon to copper, in the form of either conventional carbon fiber or diamond particles, is a good solution. This paper deals with the design of heat sink material which requires that a thermal conductivity greater than that of the copper and a lower CTE be obtained. Though it is theoretically clear that carbonreinforced copper will lead to high thermal conductivity values and low CTE, this is not practically achieved because of the effects of dispersion, interfaces and porosities.

Four different composite materials with copper or copper alloys as matrices and carbon fibers, carbon nano fibers or diamond particles as reinforcement have been examined. Also, various interface treatment between copper and carbon, to increase the thermomechanical properties of the composite and to optimize the property transfer between the matrix and the reinforcement have been described.

In the case of copper/carbon fibers composites, the orientation of the carbon fibers in the matrix induces anisotropic properties of the composite. Due to the processing method, the thermal conductivity parallel to the loading direction, which shows lower thermal conductivity of the composite has been measured. The CTE has been measured perpendicular to the loading direction. The results obtained for $\mathrm{Cu} / \mathrm{CF}$ composites prepared with the same amount (30 vol. \%) of the same carbon fibers (CN80C), but with different type of copper-based matrices do not show any change induced by the addition of an alloying element (chromium or boron) on the thermal conductivity of the composite compare to the $\mathrm{Cu} / \mathrm{CF}$ reference composite. We have also demonstrated that the addition of an alloying element $(\mathrm{Cr}$ or $\mathrm{B}$ ) creates a strong chemical link between the matrix and the reinforcement, which is expected to increase the thermal transfer. Nevertheless, the low thermal conductivity of these carbide interphases $\left(\mathrm{Cr}_{3} \mathrm{C}_{2}\right.$ or $\left.\mathrm{B}_{4} \mathrm{C}\right)$ may increase the thermal resistance at the copper-carbon interface. Therefore, the positive effect induced by the chemical bond is balanced by the negative effect induced by the thermal resistance of the interfacial carbide. Experimental results on CTE show a different behavior. Indeed, 
Emerging Materials Research

Volume 1 Issue EMR2
The role of controlled interfaces in

the thermal management of

copper-carbon composites

Silvain et al. whatever be the carbon fiber type, $\mathrm{CTE}$ of the $\mathrm{Cu}-\mathrm{X} / \mathrm{CF}$ composite are always lower than the CTE of the $\mathrm{Cu} / \mathrm{CF}$ reference one. In that way, the interfacial chemical bonds induced by the carbide formation lead to a higher transfer of thermomechanical properties from the matrix to the reinforcement and, therefore, tend to lower the CTE of the final composite.

The optimized interfaces obtained with this method give a higher thermal conductivity of the final composites compared to the $\mathrm{Cu}-\mathrm{X} /$ $\mathrm{D}_{30}$. Indeed, this technique allows to create a chemical link between the copper and the diamond through C-O-P-O-Cu and/or C-P-O-Cu bridges which have a thermal conductivity nearer to copper than carbides. Therefore, the interfacial thermal resistance is lower than with carbide elements and the thermal conductivity is higher.

The thermal conductivities of composites prepared with an interfacial treatment, $\mathrm{Cu} / \mathrm{D}_{30-\mathrm{Cu} \text { dots }}$ and $\mathrm{Cu}-\mathrm{X} / \mathrm{D}_{30}$, are greater than pure copper $(400 \mathrm{~W} / \mathrm{m} / \mathrm{K})$ and twice that of the $\mathrm{Cu} / \mathrm{D}_{30}$ reference composite. The use of an alloying element (chromium or boron) for creating a carbide interphase at the copper/diamond interface increases the final thermal conductivity of the composite. Even if this interface is not perfect, because of the low thermal conductivities of the carbides $\left(\mathrm{Cr}_{3} \mathrm{C}_{2}\right.$ and $\left.\mathrm{B}_{4} \mathrm{C}\right)$, the strong chemical interphase decreases the interfacial thermal resistance of the composite compared to the reference one and allows thermal transfer between the matrix and the reinforcement. Therefore, the liquid route induces a higher interfacial thermal resistance in the composite.

In conclusion, the thermal analyses clearly indicate that optimized interfacial treatments are essential in achieving high thermomechanical properties for these composites, with immiscible chemistry and disparate size difference. However, to have a comprehensive understanding of the effect of chemistry design, process parameters, thermomechanical treatments on the final desired properties (e.g. desired combination of TC and CTE), a focused work is underway in our group. In any case, the CTE results obtained with a chemical interphase $\left(\mathrm{Cr}_{3} \mathrm{C}_{2}\right.$ or $\left.\mathrm{B}_{4} \mathrm{C}\right)$ has already proven beyond doubt that such an approach is clearly possible.

In addition, the evolution of these thermal properties when the materials or products are subjected to in-service thermal cycling should be carefully investigated.

\section{Acknowledgments}

The authors would like to thank the French "Délégation Générale pour l'Armement" and the Region Aquitaine for its financial support.

\section{REFERENCES}

Bouvard D (2007) Powder Metallurgy. ISTE Publishing Company, London, UK.
Chu K, Liu Z, Chengchang J et al. (2010) Thermal conductivity of SPS consolidated $\mathrm{Cu}$ /diamond composites with $\mathrm{Cr}$-coated diamond particles. Journal of Alloys and Compounds, 490: 453-458.

Corbin SF, hao-jie ZX, Henien H and Apte PS (1999) Functionally grated metal /ceramic composites by tape casting, lamination and infiltration. Materials Science and Engineering 532: 192-203.

Geffroy PM and Silvain JF (2007) Structural and thermal properties of hot pressed $\mathrm{Cu} / \mathrm{C}$ matrix composites materials used for the thermal management of high power electronic devices. Materials Science Forum 534-536: 1505-1508.

Geoffroy PM, Chartier T and Silvain JF (2007) Preparation by tape casting and hot pressing of copper carbon composites films. Journal of the European Ceramic Society 27: 291-299.

Jiangs X, Herricks T and Xia Y (2002) CuO nanowires can be synthesized by heating copper substrates in air. Nano Letters 2: 12

Luedtke A (2004) Thermal management materials for highperformance applications. Advanced Engineering Materials 6: 142-144.

Mathias JD, Geffroy PM and Silvain JF (2009, August) Architectural optimization for microelectronic packaging. Applied Thermal Engineering 29: 2391-2395.

PLANSEE (2009) Diamond composite materials, catalogue.

Saums DL (2004) Developments in selective high thermal conductivity orientation in CTE-compatible substrate and package component materials. 20th IEEE Semi-Therm Symposium, 38-45.

Schubert T, Ciupinski L, Zielinski W et al. (2008) Interfacial characterization of $\mathrm{Cu} /$ diamond composites prepared by powder metallurgy for heat sink applications. Scripta Materialia 58: 263-266.

Silvain JF, Denis-Lutard V, Geoffroy PM and Heintz JM (2010) Adaptive composite materials with novel architectures. Materials Science Forum, 631-632: 149-154.

Silvain JF, Vincent C, Heintz JM and Chandra N (2009) Novel processing and characterization of $\mathrm{Cu} / \mathrm{CNF}$ nanocomposite for high thermal conductivity applications. Composites Science and Technology 69: 2474-2484.

Silvain JF, Heintz JM and Vincent C (2010, July 5) Procédé de formation d'un dépôt métallique à la surface d'un substrat et applications. French patent FR1055422. (in French).

Veillère A (2009) Drains thermiques adaptatifs : Cuivre allié / Fibres de carbone. $\mathrm{PhD}$ thesis, Université de Bordeaux 1, France. (in French).

Veillere A, Heintz JM, Chandra N et al. (2012). Influence of the interface structure on the thermo-mechanical properties of $\mathrm{Cu}-\mathrm{X}(\mathrm{X}=\mathrm{Cr}$ or $\mathrm{B}) /$ Carbon fiber composites. Materials Research Bulletin 47: 500-503.

Veillere A, Sundaramurthy A, Heintz JM et al. (2011). Relationship between interphase chemistry and mechanical 
Emerging Materials Research

Volume 1 Issue EMR2
The role of controlled interfaces in

the thermal management of

copper-carbon composites

Silvain et al. properties at the scale of micron in $\mathrm{Cu}-\mathrm{Cr} / \mathrm{CF}$ composite. Acta Materialia 59: 1445-1455.

Vincent C (2008) Le composite cuivre / nanofibre de carbone. PhD thesis, Université de Bordeaux 1, France. (in French).

Weber L and Tavangar R (2007) On the influence of active element content on the thermal conductivity and thermal expansion of $\mathrm{Cu}-\mathrm{X}(\mathrm{X}=\mathrm{Cr}, \mathrm{B})$ diamond composites. Scripta Materialia 57: 988-991.
Xia Y, Song YQ, Lin CG, Cui S and Fang ZZ (2009) Effect of carbide formers on the microstructure and thermal conductivity of diamond-Cu composites for heat sink materials. Transactions of Nonferrous Metals Society of China 19: 1161-1166.

Zweben C (1998) Advances in composite materials for thermal management in electronic packaging. Journal of Management 50: $47-51$.

Zweben C (2006) High-performance thermal management material. Advanced Packaging 15: 1-5.

\section{WHAT DO YOU THINK?}

To discuss this paper, please email up to 500 words to the managing editor at emr@icepublishing.com

Your contribution will be forwarded to the author(s) for a reply and, if considered appropriate by the editor-inchief, will be published as a discussion in a future issue of the journal.

ICE Science journals rely entirely on contributions sent in by professionals, academics and students coming from the field of materials science and engineering. Articles should be within 5000-7000 words long (short communications and opinion articles should be within 2000 words long), with adequate illustrations and references. To access our author guidelines and how to submit your paper, please refer to the journal website at www.icevirtuallibrary.com/emr 